\title{
Application of LiDAR-Derived Data using Multi-Criteria Evaluation (MCE) and Stochastic Modelling; A Flood Risk Analysis of the Mersey River, Nova Scotia
}

\author{
Daniel E. Almuina Pica, Alejandro Nieto Rodriguez, Tyler Stange \\ Department of Geography, Environment, and Geomatics, College of Social and Applied Human Sciences, University of Guelph, \\ Guelph, ON Canada. Faculty supervisor: Dr. Ben DeVries. \\ For correspondence, please email: ale.nieto00@hotmail.com, elliot.almuinapica@gmail.com, tyler.email.22@gmail.com
}

\begin{abstract}
The Maritime province of Nova Scotia has seen coastal flooding become a more frequent phenomenon during the past decades due to the changing climate. This has influenced the interest of the provincial and federal governments in flood risk modelling, who often incorporate Geographic Information Systems (GIS) as useful tools in their analysis. Incorporating digital elevation models (DEMs) derived from light imaging detection and ranging (LiDAR) point clouds in their workflows is the next step in hydrological analysis, as LiDAR-derived DEMs offer high resolution data for the analysis of flood risk without the need to rely on biotic or hydrological data. Consistent with this theme, this study models the effects of inland flooding in the low relief landscape of the Mersey River, located in Queen's County, Nova Scotia, with special attention to infrastructure built along the river network. The analysis includes multi-criteria evaluation (MCE) methods coupled with a stochastic simulation approach in order to determine areas where vulnerability is most certain. Results indicate that high flood risk is present in urbanised areas within $1 \mathrm{~km}$ of the Mersey River at a low degree of uncertainty, making these areas the best candidates for flood-preventive measures. The accuracy provided by LiDAR-derived DEMs supports a high-quality workflow for the MCE and DEM error analysis, proving their utility for floodplain delineation. The methods and results of this study show the applications of MCE and stochastic processes on flood risk modelling, closing the gap in the literature and giving space for much needed future work.
\end{abstract}

Keywords: flood risk, LiDAR, multi-criteria evaluation, uncertainty, stochastic simulation, Monte-Carlo method

\section{Introduction}

Floods represent one of the costliest environmental hazards to coastal communities, threatening infrastructure, and human capital alike (Jha et al., 2012, p. 21). These issues are accentuated in an urban setting, as population density peaks in cities where property and assets have a higher economic cost and use (Jha et al., 2012, pp. 21-22). Furthermore, a changing climate regime is expected to increase flood intensity in the following decades, making this an 
extremely important topic to consider for further reviews (World Meteorological Organization \& Global Water Partnership, 2009, p. 5).

Flood risk modelling has gained traction in the last decade as a key tool for predicting flood inundation zones and providing reliable information on risk associated with flooding events (Webster et al., 2004). Governments and private institutions often use Geographic Information Systems (GIS) for this purpose, where, aided by computer-generated models, they can improve damage estimation in case of a natural disaster. Light imaging detection and ranging (LiDAR)derived data can be quite useful for this purpose, as high-resolution digital elevation models (DEMs) allow for more accurate floodplain modelling and more certain predictions of flood risk (Haile et al., 2005).

Here the integration of GIS and multi-criteria evaluation (MCE) comes into play. By using these techniques, GIS specialists are able to evaluate complex spatial problems when more than one variable is involved (Carver, 1991). Although MCEs are commonly used for creating suitability maps (Eastman, 1999; Hazarika et al., 2018), there is also extensive evidence in the literature showing their importance in flood risk modelling (Hazarika et al., 2018; Khan et al., 2018; Rahmati et al., 2018).

There are, however, legitimate concerns regarding the use of MCEs for this purpose. Errors present in the DEM, known as the root-mean-square-error (RMSE), lead to uncertainties in the model results, which may make the analysis unreliable. In order to assess this, a probabilistic approach can be taken, using stochastic (Monte-Carlo) simulation to run a predetermined number of iterations of the MCE workflow, subjecting its criteria to the fluctuations derived from the RMSE. Stochastic processes are sometimes used in flood risk modelling and MCE independently (Celik et al., 2019), but there is no literature which combines stochastic modelling and MCE analysis when evaluating flood risk. This study therefore aims to fill in the existing void in the literature, and hopefully encourage other authors to adopt similar techniques in their own research.

\section{Research Purpose}

This study creates a flood risk model for the area surrounding the Mersey River, located in Queens County, Nova Scotia, using MCE methodology. A stochastic simulation is then performed in order to analyse the sensitivity of the MCE output to RMSE in the DEM, differentiating at-risk areas with varying degrees of uncertainty.

\section{Key Definitions}

Herein "risk" is defined as the combination of probability and consequences of a flood event if it were to happen, while "uncertainty" is defined as the likelihood of any of those estimated risk values to vary from reality. The "real" risk values would be those that would be obtained if error were to be absent from the workflow.

\section{Study Area}

The study is focused on southwestern Nova Scotia. The chosen strip of the Mersey River extends for $17 \mathrm{~km}$ and borders two major urban townships, Milton, and Liverpool, while touching on the periphery of another, Bristol, as seen in Figure 1. The combined population of these three towns is around 3,500 residents (Peterson, 2015). Also along this low relief strip of river are roadways containing peri-urban development along with automotive and railway bridges stretching over the river and spillways. The Mersey River contains Nova Scotia's largest 
and second most productive hydroelectric network, consisting of 6 generating stations, 33 dams, 17 spillways, and 3 canals. This hydroelectric system is a critical part of Nova Scotia's electricity network, ensuring power supply for a large part of the southern counties.

Deforestation in the study site is a common feature, exemplified by several "bare land" patches in proximity to the riverbank. These patches are susceptible to lower infiltration rates than those of forested land, thus increasing the frequency and intensity of potential floods (Regüés et al., 2017).

\section{Methods}

\section{Data Needs}

LiDAR datasets provide a high-resolution representation of elevation data, something which is particularly important when modelling complex topography, according to Haile et al. (2005). This characteristic of LiDAR datasets makes them an invaluable tool for modelling drainage networks, representing land-use and infrastructure in 3D view, and mapping floodplain extent (Haile et al., 2005). Six DEM raster tiles at 1-metre resolution were used in this study, all derived from LiDAR data gathered by Leading Edge Geomatics (2019). Land use data was obtained through Agriculture and Agri-Food Canada which, in 2010, created the Canada-wide land use dataset at a 30-metre resolution using classified satellite imagery. The last data component used in the study was a vector polygon which represented the extent of the Mersey River from the Port of Liverpool all the way up to Sandy Bottom Lake.

\section{Data Cleaning and Pre-Processing Methods}

Each of the layers described above was reprojected to the coordinate system corresponding to the geographic location of the study area, NAD_1983_UTM_Zone_20N, which was used by every layer created onwards in our report. The six DEM tiles were mosaicked and then hydrologically conditioned using breaching to ensure flow across depressions. This breached DEM was used to derive all terrain attributes used in the analysis.

\section{Criteria Selection and Creation}

The criteria included in the MCE workflow were influenced by the methodology used in Hazarika et al. (2018), Khan et al. (2018), and Rahmati et al. (2018), which involved parameters that had a high degree of influence in river floods. Figure 2 offers a visual representation of these criteria, which are summarised here:

1. Slope - Slope affects the velocity at which water travels through a drainage channel. The lower the slope, the flatter the terrain, and the more likely it is for water to flow through the determined location (Kandilioti \& Makropoulos, 2011, p. 447). By contrast, steeper ascending paths will limit the extent of the floodplain, effectively reducing the impact of the flooding event (Mohamed Elmoustafa, 2012, p. 328).

2. Proximity to rivers - Flooding is more common in areas closer to rivers. Therefore, the closer a certain location is to the river, the higher the risk is (Rincón et al., 2018). The rasterized river extent was used to generate a downslope distance to stream (DDTS) raster, which represents the distance from all cells in the raster to the closest point of the stream measured along the downslope flow path of the water. 
3. HAND - Height above nearest drainage (HAND) represents the difference in elevation between a location and its nearest stream cell. The higher the value associated with the HAND criterion, the lower the risk of flooding will be for a certain location (Souza Santos et al., 2021).

4. Proximity to dams - Dams help regulate water flow and are also a source of hydropower for the people of Bristol, Liverpool, and Milton. In case of a flooding event, there is risk of dam failure which, depending on the water volume stored by the dam, will determine the degree of risk that dam poses to the neighbouring lands (CVCOG, 2012). The addition of this criterion was made based on the unique characteristics of our study site when compared to other studies (see Introduction); three dams affect water flow along the Mersey River, which were digitised and rasterized and used to derive a Euclidean distance raster from their location to the rest of the cells in the study site.

5. Land use - Due to the impervious nature of asphalt, urban areas tend to carry more water as overland flow during a flooding event. Permeable soils, such as forested areas and bare land, on the other hand, have a higher infiltration rate than asphalt, leading to a significant percentage of water being lost to infiltration in case of a rainfall or flooding event (Markovič et al., 2014). This raster was resampled to match the 1-metre resolution of the other layers.

\section{Multi-Criteria Evaluation (MCE)}

Two key steps were performed prior to running the MCE for this study:

1. Rescaling of criteria factors - This step consisted of rescaling all criteria to a 0 to 100 scale. Values approaching 100 are considered high risk while values approaching 0 are considered low risk. All criteria were rescaled using a linear stretch, as shown in Equation 1.

2. Determination of criteria weights - Weighting of the rescaled criteria was accomplished using a pairwise matrix, as shown in Table 1, since the pairwise method is the most studied. Rankings in the matrix were determined based on the literature referenced by each researcher independently. After weights were determined, they were combined with the criteria to perform the MCE in a similar manner to that shown in Equation 2.

\section{Stochastic Simulation (Monte-Carlo Method)}

Stochastic simulations are useful for estimating probability distributions of an output when one or more inputs have a component that is subjective to random variability (Graham \& Talay 2015; Patidar et al., 2017). The RMSE of the DEM $(6.6 \mathrm{~cm})$ was the component taken as reference to see the effect it had on the overall results. The simulation shown in Figure 3 was run for 50 iterations (the number 50 was chosen as it would produce an accurate dataset over a shorter simulation period). Its outputs show an average of calculated flood risk over the floodplain extent to which three different uncertainty thresholds are applied. Each one of these threshold scenarios, shown in Figure 5, represent low, moderate, and high levels of uncertainty on the generated MCE map. Uncertainty thresholds for Figure 5, maps a), b), and c) equal a threshold of $15 \%, 25 \%$, and $40 \%$ respectively. This means that if the simulation allocates a value equal or above the threshold for any raster cell, then there is a higher likelihood of MCE validation, and this reaffirms the probability of a flood, which is indicated as high risk and is coloured red. These uncertainty maps should be used together with the MCE (Figure 4), as they serve as validation tools for the results presented in it. 


\section{Results and Discussion}

\section{MCE Weights and LiDAR Discussion}

Criteria values used in the MCE presented in Table 1 emphasise land use as the heaviest weighted criterion, as urban infrastructure is heavily impacted by flooding. These include roadways, urban centres, and rural areas that hug the bank of the Mersey River. Slope plays a crucial role in the containment of flooding, as demonstrated when one reaches the outer edges of the HAND extent ( 0.4-0.7 km perpendicular to the river direction). At this distance, the relief of the landscape halts the lateral progression of floodwaters, effectively defining the maximum extent of the final MCE map. These results obtained from analysis of the low relief landscape of Nova Scotia can be compared with Rahmati et al. (2015) and Rennó et al. (2011), who used HAND methods for high relief floodplains and showed that they do not extend nearly as much as those in low relief areas. However, the volume of floodwater accumulated in the former would be greater, potentially causing more water damage to essential structures such as power lines and residential areas.

\section{Mersey River MCE Analysis}

Flood risk calculated over the floodplain extent is shown in Figure 4. The results presented in Figure 4, maps a) and b) show significantly high flood risk mainly in the urban sprawl in Liverpool, Bristol, and Milton, with Liverpool being the area of highest vulnerability among the three. This is due to Liverpool being the lowest elevation town in the study site, sitting at $22-31 \mathrm{~m}$ above sea level, coupled with the fact that it is the densest urban area and the heaviest weighted sector of our MCE. A high-risk cluster occurs as the flood path continues south away from Liverpool along Nova Scotia (NS) Highway 3, then flowing into the wetlands and marshlands that make up the Meadow, Round, Neck, and Bar Ponds, where water could potentially flow laterally into the surrounding wetland and/or overflow onto the highway.

The urban extent of the Bristol Harbour also shows areas of high risk with most of them identified as parking lots and yards. These impermeable surfaces propagate floodwaters easily due to overland flow, making floods larger and more dangerous when these areas are affected by a flooding event. The propagation is also amplified by the material's surface roughness coefficient (Arcement et al., 1989), which determines the trajectory of the floodwaters. This variable is dependent on the channel width, length, and induced drag on the fluid across the medium (see Criteria Selection and Creation). The reverse also occurs in vegetated areas, where water passing over the surface is lost to infiltration, and thus overland flow is significantly reduced. However, areas away from urbanised land can still have values at a moderate to high risk, as flooding can occur all the way to the edge of the floodplain but will be stopped in areas of high slope in the landscape. Milton shows values at the highest risk threshold due to its proximity to two dams located upstream from it and due to the town being at a narrow point in the river, bottlenecking the accumulation of floodwater, which eventually could spill out and become overland flow.

\section{Analysis of Floodplain Sensitivity Maps}

The stochastic (Monte-Carlo) simulation results are used to validate the findings of the MCE map displayed in Figure 4. This is done by determining whether the RMSE of the DEM caused uncertainty in the MCE output at its highest risk locations. In Figure 5, areas showing high risk in the MCE also display low uncertainty at the lowest uncertainty threshold (map a), 
indicating that the MCE results are validated and that the RMSE did not have significant influence on its output. These high-risk areas should be the biggest source of concern for the municipal and provincial governments in the near future, and flood mitigation measures would be recommended to protect the vulnerable urban areas in these locations.

Low uncertainty areas in Figure 5, map a) are situated in the greater Liverpool area and Bristol Harbour, shown in the darker red colours, with small patches of flooding along the bank of the river, north-west of Milton, and the two nearest dam locations. This means that at the lowest possible threshold of uncertainty in our MCE output is the urban and industrial areas, roadways, and causeways within $1 \mathrm{~km}$ of the bank. Therefore, these areas are at the highest priority for flood prevention. Towards the southern end of the Liverpool urban extent, the simulation indicates low to moderate uncertainty on the flooding reaching the wetlands discussed in the previous section, indicating validity in the MCE for this attribute. Other small patches of low uncertainty are scattered throughout the HAND extent, which appears mostly grey, but are always within proximity to the river network.

The moderate threshold in Figure 5, map b) shows a delineation output that is nearly identical to the flood map in Figure 4, indicating that uncertainty due to error is not a factor to invalidate the results. Cells with low uncertainty areas extend south westbound of the NS Highway 3 networks, including the multi-basin/pond network along the wetlands. Apart from the elevated roads and bridge networks within north and south Liverpool, a considerable amount of the urban scape has little uncertainty and subsequently validates the MCE for predicting flood risk occurring in these areas. As seen in Figure 5, map b), regions of higher uncertainty (in grey) coincide with areas of moderate flood risk in the MCE.

The highest threshold in Figure 5, map c) shows a larger extent where uncertainty values approximate $0 \%$, matching almost the entirety of the floodplain. Areas in the MCE map (Figure 4) attributed with low flood risk values are determined to be of high uncertainty in the stochastic model. These areas should not be deemed as "safe" in case of a flooding event. On the contrary, due to the high uncertainty values associated with them, the MCE does not accurately predict risk at their locations and should therefore be independently investigated to assess their actual vulnerability in the case of a flooding event. The results of the stochastic simulation demonstrated that the elevation error in the DEM does not compromise the validity of the initial MCE analysis in properly modelling areas at risk where flood mitigation measures could and should be implemented.

\section{Future Work and Implications}


The floodplain delineation analysis presented in this study only shows one of many existing methods for assessing flood risk in low relief landscapes. Further models of the Mersey River floodplain would require additional historical and hydrological data for the river that unfortunately was not available at the time the study began. Soil and biotic data, together with a detailed description of industrial activity in the area, would also serve to increase the complexity of the model, but would also increase error propagation across the workflow. Following recommendations in Lindsay et al. (2008) for future works in hydrological modelling, error management should be a focus if uncertainty is to be minimised in the final output of the project.

The MCE analysis determined the flood risk associated with the Mersey River waters while the stochastic simulation determined the effect RMSE had on our findings due to random variation, ultimately leading to the validation of the MCE. The idea of using stochastic analysis to deal with uncertainty in the workflow is shared amongst many researchers, including Lindsay et al. (2008) and Wolock et al. (1994), who stressed the importance of processing/managing error in their studies.

\section{Conclusions}

Urban areas surrounding the Mersey River in Nova Scotia are expected to be at a higher risk of flooding events than any other land type in the region. Land use is an important criterion in delineating flood patterns, as the transport method of water will depend on the surface type, with overland flow predominating in urban areas. In addition, urban areas have higher economic value and higher population density than other land types, further accentuating the associated risks coming from floods. This premise was supported and reinforced by the MCE model and the stochastic simulation analysis. Operating these two methods in conjunction gave authority for this study to expand on the limited literature on the topic of combining stochastic modelling with LiDAR DEM-based MCE. The results put the cities of Liverpool, Bristol, and Milton at a high risk, making them the best targets for the development of risk mitigation programs. It is intended that the combination of MCE and stochastic processes used in this study could serve as a reference for flood risk work performed in different locations, as assessing uncertainty in the source data is of key importance for conducting a robust analysis.

\section{Acknowledgements}

We would like to thank our professor, Dr. Ben DeVries, as well as Nigel van Nieuwenhuizen [MSc] for their instruction and guidance in making this paper possible. They are huge inspirations for budding GIS scientists such as ourselves. The code that was used for the stochastic modelling was based upon Nigel's source code and can be found at this link: https://github.com/elias10427/Stochastic-Modelling-for-hydrological-DEM.

\section{References}

Arcement, G. J., \& Schneider, V. R. (1989). Guide for selecting Manning's roughness coefficients for natural channels and flood plains. 
Carver, S. J. (1991). Integrating multi-criteria evaluation with geographical information systems. International Journal of Geographical Information System, 5(3), 321-339. https://doi.org/10.1080/02693799108927858

Casas, A., Benito, G., Thorndycraft, V. R., \& Rico, M. (2006). The topographic data source of digital terrain models as a key element in the accuracy of hydraulic flood modelling. Earth Surface Processes and Landforms: The Journal of the British Geomorphological Research Group, 31(4), 444-456. https://doi.org/10.1002/esp.1278

Celik, E., Gul, M., Yucesan, M., \& Mete, S. (2019). Stochastic multi-criteria decision- making: An overview of methods and applications. Beni-Suef University Journal of Basic and Applied Sciences, 8(1). https://doi:10.1186/s43088-019-0005-0

Concho Valley Council Of Governments (CVCOG). (2012). Hazard Mitigation Plan Update Dam Failure. Retrieved March 30, 2021, from http://www.cvcog.org/cvcog/docs/Public\%20CVCOG\%20Hazard\%20Mitigation\%20Plan \%20Update\%202012-2017.pdf

Eastman, J. R. (1999). Multi-criteria evaluation and GIS. Geographical information systems, 1(1), 493-502.

Elmoustafa, A. M. (2012). Weighted normalized risk factor for floods risk assessment. Ain Shams Engineering Journal, 3(4), 327-332. https://doi.org/10.1016/j.asej.2012.04.001

Graham, C., \& Talay, D. (2013). Stochastic simulation and Monte Carlo methods: mathematical foundations of stochastic simulation (Vol. 68). Springer Science \& Business Media.

GRASS Development Team. (2021, February 05). GRASS GIS - Bringing advanced geospatial technologies to the world. Retrieved March 30, 2021, from https://grass.osgeo.org/

Haile, A. T., \& Rientjes, T. H. M. (2005). Effects of LiDAR DEM resolution in flood modelling: a model sensitivity study for the city of Tegucigalpa, Honduras. Isprs wg iii/3, iii/4, 3, 12-14.

jackie_pc (2021), Updated Mersey River shapefile up to Sandy Bottom Lake (Version 1), Rights: jackie_pc, ArcGIS Online.

Kandilioti, G., \& Makropoulos, C. (2011). Preliminary flood risk assessment: The case of Athens. Natural Hazards, 61(2), 441-468. https://doi:10.1007/s11069-011-9930-514

Lamichhane N, \& Sharma S. (2017). Development of Flood Warning System and Flood Inundation Mapping Using Field Survey and LiDAR Data for the Grand River near the City of Painesville, Ohio. Hydrology, 4(2), 1-15. https://doi.org/10.3390/hydrology4020024

Lindsay, J. B., \& Evans, M. G. (2008). The influence of elevation error on the morphometrics of 
channel networks extracted from DEMs and the implications for hydrological modelling. Hydrological Processes: An International Journal, 22(11), 1588-1603.

https://doi.org/10.1002/hyp.6728

Lindsay, J. (2021). Whiteboxtools. Retrieved March 30, 2021, from

https://iblindsay.github.io/ghrg/WhiteboxTools/index.html

MacDonald, C., \& Webster, T. (2016). Flood Risk Analysis of the Halifax Harbour to Support Evacuation Modeling. Technical Report, Applied Geomatics Research Group, NSCC Middleton, NS.

Markovič, G., Zeleňáková, M., Káposztásová, D., \& Hudáková, G. (2014). Rainwater infiltration in the urban areas. WIT Transactions on Ecology and The Environment, 181, 313-320. https://doi:10.2495/EID140271

McGuigan, K., Webster, T., \& Collins, K. (2015). A flood risk assessment of the LaHave River watershed, Canada using GIS techniques and an unstructured grid combined rivercoastal hydrodynamic model. Journal of Marine Science and Engineering, 3(3), 10931116. https://doi.org/10.3390/jmse3031093

Mohamed Elmoustafa, A. (2012). Weighted normalized risk factor for floods risk assessment. Ain Shams Engineering Journal, 3(4), 327-332. https://doi.org/10.1016/j.asej.2012.04.001

Nova Scotia Data Explorer (2019), 201901_RAW_DEM.tif (Version 2019) [GeoTIFF DEM dataset] Producer: Leading Edge Geomatics

Nova Scotia Environment. (2017, December 10). Flooding: Climate Change. Retrieved January 26, 2021, from https://novascotia.ca/nse/climate-change/nsfaf-flooding.asp

Nova Scotia Power (2018). Nova Scotia Incorporated Hydro Asset Study (Redacted). Retrieved January 28, 2021, from https://irp.nspower.ca/files/key-documents/backgroundmaterials/20181221-NS-Power-Hydro-Asset-Study-REDACTED.pdf

Open Source Geospatial Foundation (2021). QGIS. Retrieved March 30, 2021, from https://qgis.org/en/site/

Patidar, S., Haynes, H., Li, J., \& Haynes, R. (2017). Stochastic modelling approach for future flood risk modelling. In Math Foresees General Assembly 2017 Presentation. Retrieved March 30, 2021, from http://www1.maths.leeds.ac.uk/mathsforesees/presentations/Patidar.pdf

Peterson, Jean. "Liverpool". The Canadian Encyclopedia, 04 March 2015, Historica Canada. https://www.thecanadianencyclopedia.ca/en/article/liverpool. Accessed 30 March 2021.

Rahmati, O., Zeinivand, H., \& Besharat, M. (2015). Flood hazard zoning in Yasooj region, Iran, 
using GIS and multi-criteria decision analysis. Geomatics, Natural Hazards and Risk, 7(3), 1000-1017. https://doi.org/10.1080/19475705.2015.1045043

Regüés, D., Badía, D., Echeverría, M., Gispert, M., Lana-Renault, N., León, J., . . SerranoMuela, P. (2017). Analysing the effect of land use and vegetation cover on soil infiltration in three contrasting environments in northeast Spain. Cuadernos De Investigación Geográfica, 43(1), 141-169. https://doi:10.18172/cig.3164

Rennó, C. D., Nobre, A. D., Cuartas, L. A., Hodnett, M., Rodrigues, G., Silveira, A., Waterloo, M., \& Saleska, S. (2011). Height Above the Nearest Drainage - a hydrologically relevant new terrain model. Journal of Hydrology, 404(1-2), 13-29. https://doi.org/10.1016/j.jhydrol.2011.03.051

Rincón, D., Khan, U. T., \& Armenakis, C. (2018). Flood risk mapping using GIS and multicriteria analysis: A greater Toronto area case study. Geosciences, 8(8), 275. https://doi.org/10.3390/geosciences8080275

Souza Santos, E. D. Koenow, Pinheiro, H. S., \& Gallo Junior, H. (2021). Height Above the Nearest Drainage to Predict Flooding Areas in São Luiz do Paraitinga, São Paulo. Floresta E Ambiente, 28(2), 1-10. https://doi:10.1590/2179-8087-floram-2020-00705

Tutton, M. (2018, March 5). Growing frequency, ferocity of Nova Scotia storm surges worries local politicians. Global News - Canada. Retrieved January 26, 2021, from https://globalnews.ca/news/4063940/nova-scotia-storm-surges/

Webster, T. L., Forbes, D. L., Dickie, S., \& Shreenan, R. (2004). Using topographic lidar to map flood risk from storm-surge events for Charlottetown, Prince Edward Island, Canada. Canadian Journal of Remote Sensing, 30(1), 64-76. https://doi.org/10.5589/m03-053

World Meteorological Organization, \& Global Water Partnership (2009). Flood Management in Changing Climate - A Tool for Integrated Flood Management (pp. 1-28, Tech. No. 14). Retrieved January 26, 2021, from https://www.gwp.org/globalassets/global/toolbox/references/flood-management-in-achanging-climate-apfm-wmogwp-2009.pdf

Wolock, D. M., \& Price, C. V. (1994). Effects of digital elevation model map scale and data resolution on a topography-based watershed model. Water Resources Research, 30(11), 3041-3052. https://doi.org/10.1029/94WR01971

Yalcin, G. (2002). Analyzing flood vulnerable areas with multicriteria evaluation [dissertation]. Middle East Technical University, Ankara. https://www.isprs.org/proceedings/xxxv/congress/comm2/papers/154.pdf

\section{Tables and Figures}

Table 1. MCE table indicating the distribution of weights amongst our analysis constraints given by each researcher and applied to the flood delineation. 


\begin{tabular}{lcccc}
\hline Our Criteria & $\begin{array}{c}\text { Almuina Pica, } \\
\text { D: Weighting }\end{array}$ & $\begin{array}{l}\text { Nieto, A: } \\
\text { Weighting }\end{array}$ & $\begin{array}{c}\text { Stange, T: } \\
\text { Weighting }\end{array}$ & Final Ranking \\
\hline Hand & 0.231 & 0.120 & 0.320 & 0.221 \\
Land use/cover & 0.408 & 0.162 & 0.250 & 0.270 \\
$\begin{array}{l}\text { Proximity to } \\
\text { dams }\end{array}$ & 0.125 & 0.150 & 0.080 & 0.118 \\
$\begin{array}{l}\text { Slope } \\
\begin{array}{l}\text { Proximity to } \\
\text { rivers }\end{array}\end{array}$ & 0.184 & 0.282 & 0.220 & 0.226 \\
\hline Total & 0.252 & 0.122 & 0.130 & 0.165 \\
\hline
\end{tabular}

Equation 1. Where OUTVAL = value of pixel in output map, INVAL = value of pixel in input map, INLO = lower value of 'stretch from' range, INUP = upper value of 'stretch from' range, OUTLO = lower value of 'stretch to' range, and OUTUP = upper value of 'stretch to' range.

OUTVAL $=(I N V A L-I N L O) \times(O U T U P-O U T L O) \div(I N U P-I N L O)+$ OUTLO

Equation 2. Where $\mathrm{C}=$ criteria, $\mathrm{W}=$ weight, $\mathrm{n}=$ upper limit, and $\mathrm{i}=$ lower limit.

$\sum i n C n W n=C 1 \times W 1+C 2 \times W 2+C 3 \times W 3+\ldots \ldots \ldots . C n \times W n$ 


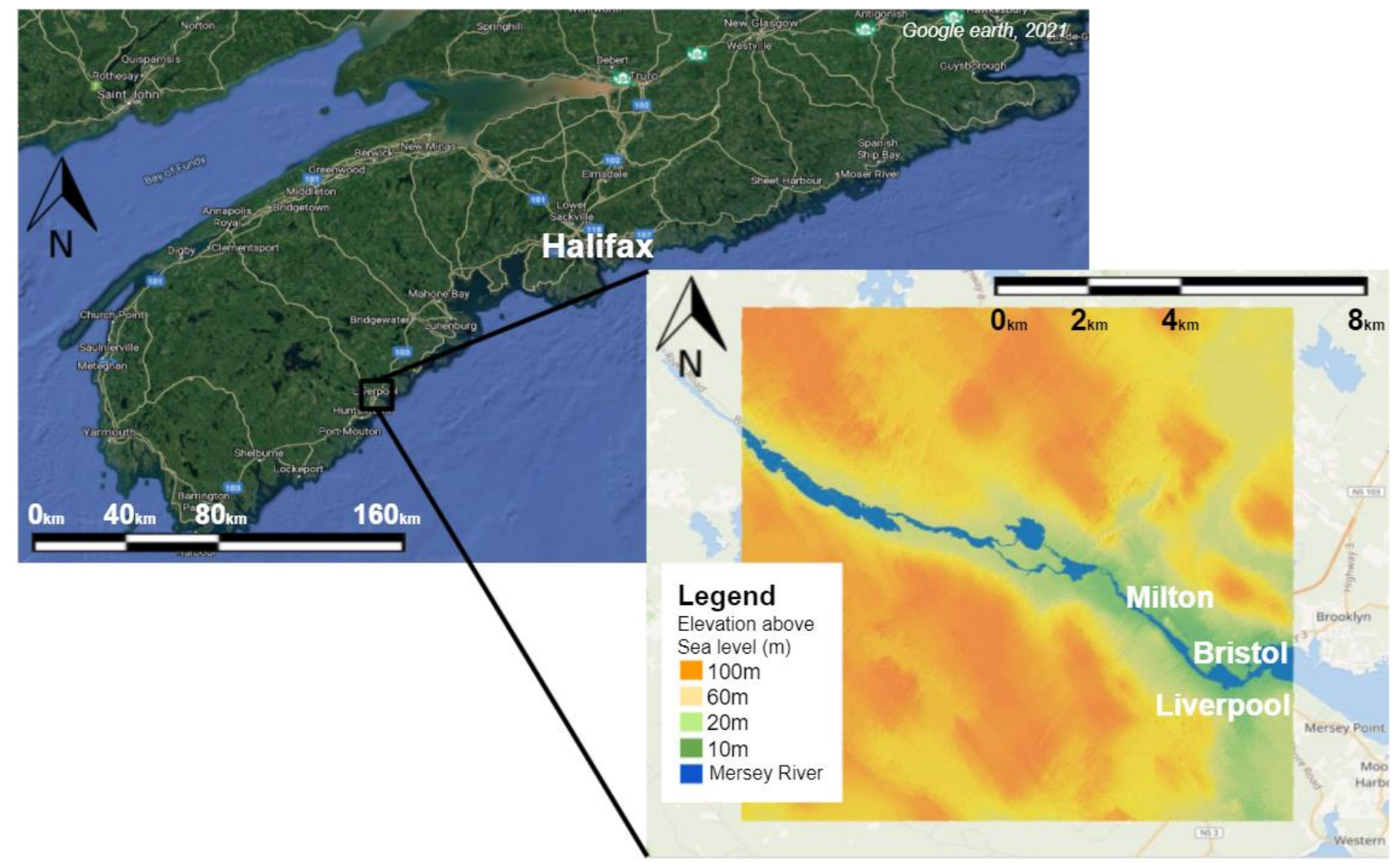

Figure 1. The study site encompasses a subsection of the Mersey River, located in proximity to Liverpool, Queens County, along the southern coast of Nova Scotia. A DEM of the study area is overlaid to show the local topography. 
a)

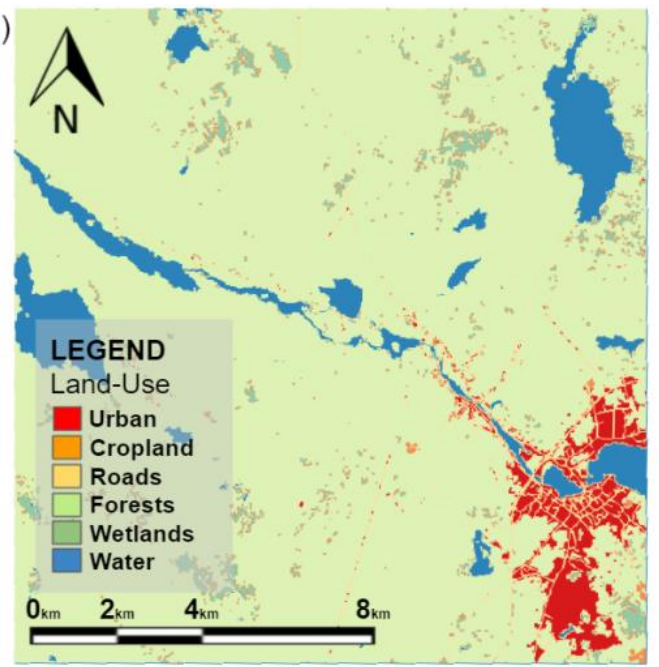

c)

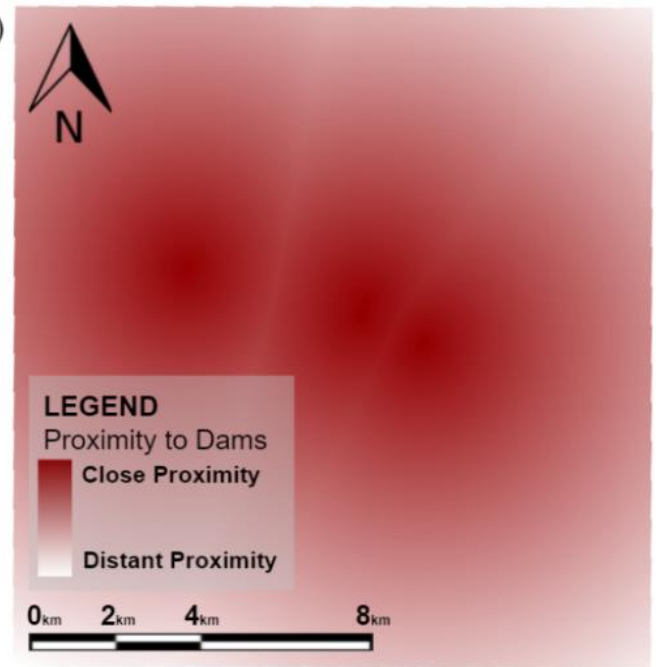

e)

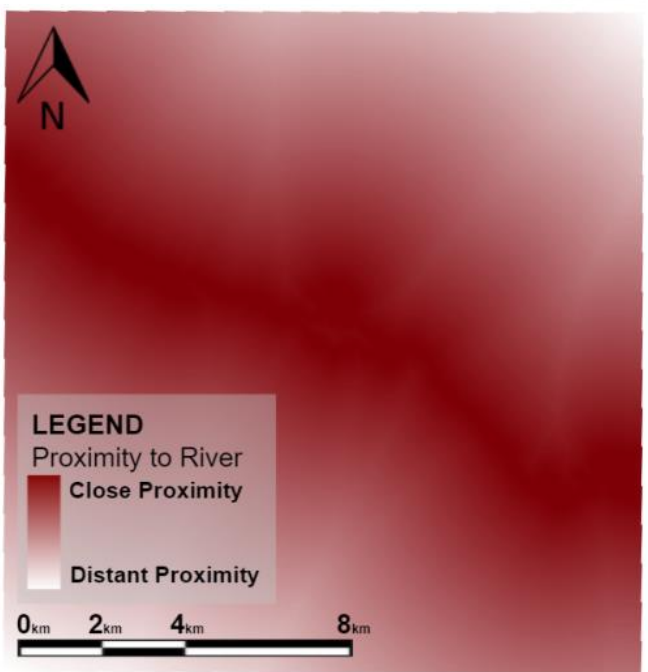

b)

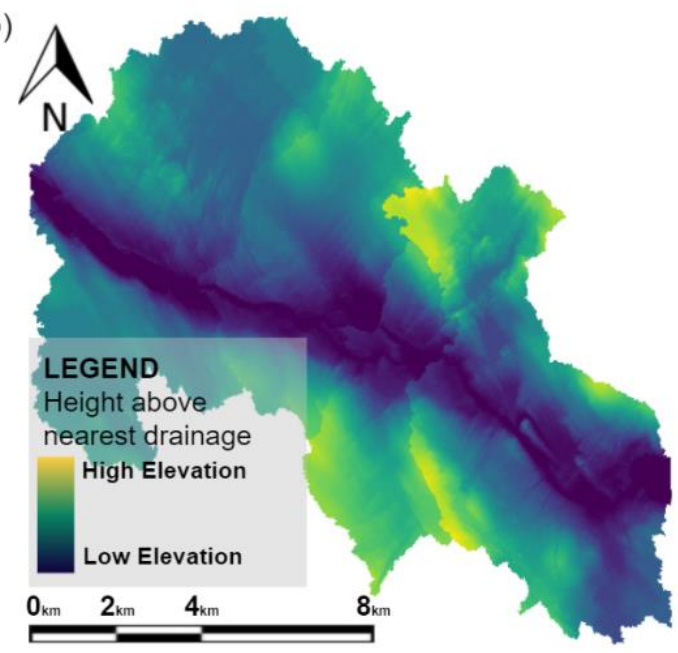

d)

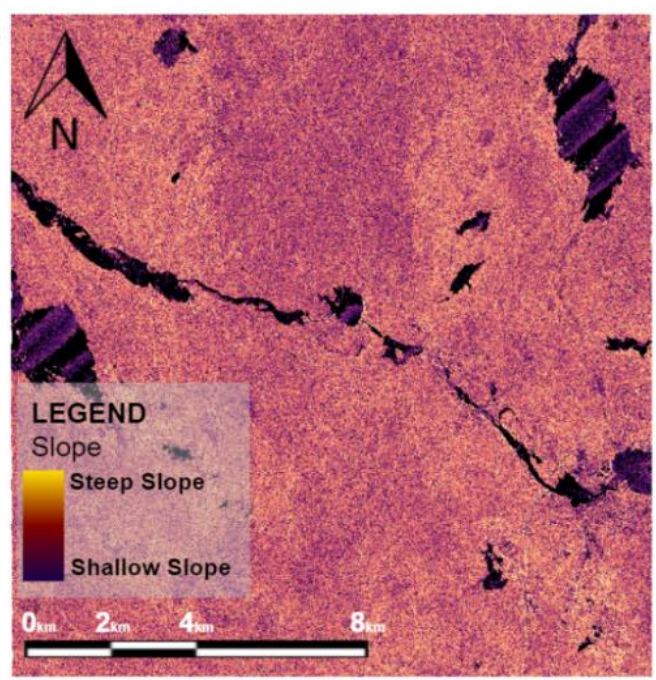

Figure 2. The visual representation of the criteria to be used in the MCE analysis. Represented as a) land use layer, b) height above nearest drainage, c) proximity to dams, d) slope, and e) proximity to rivers. 


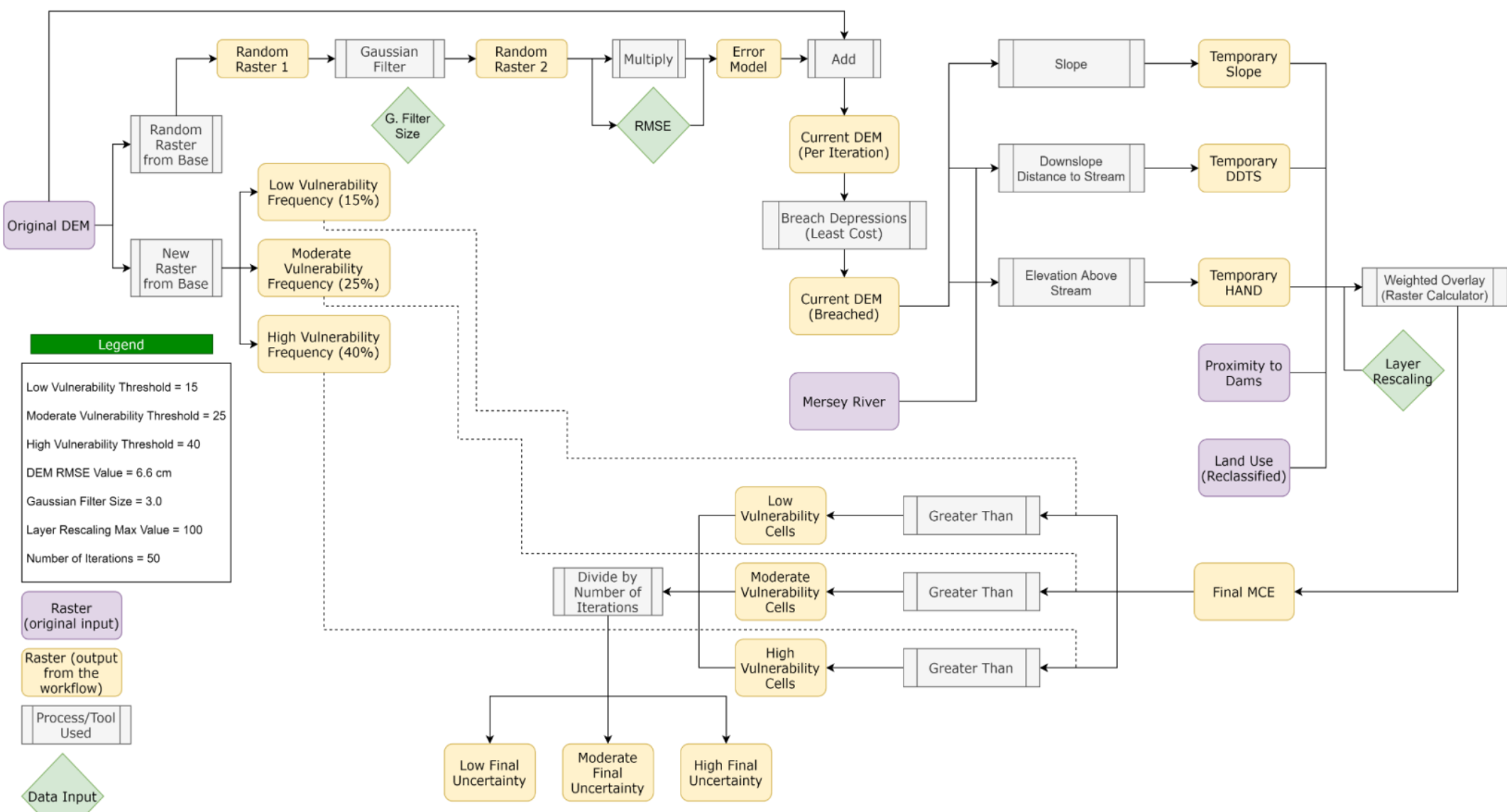

Figure 3. Flowchart illustrating the steps and processes used to create the stochastic layers using a series of for loops. 
a)

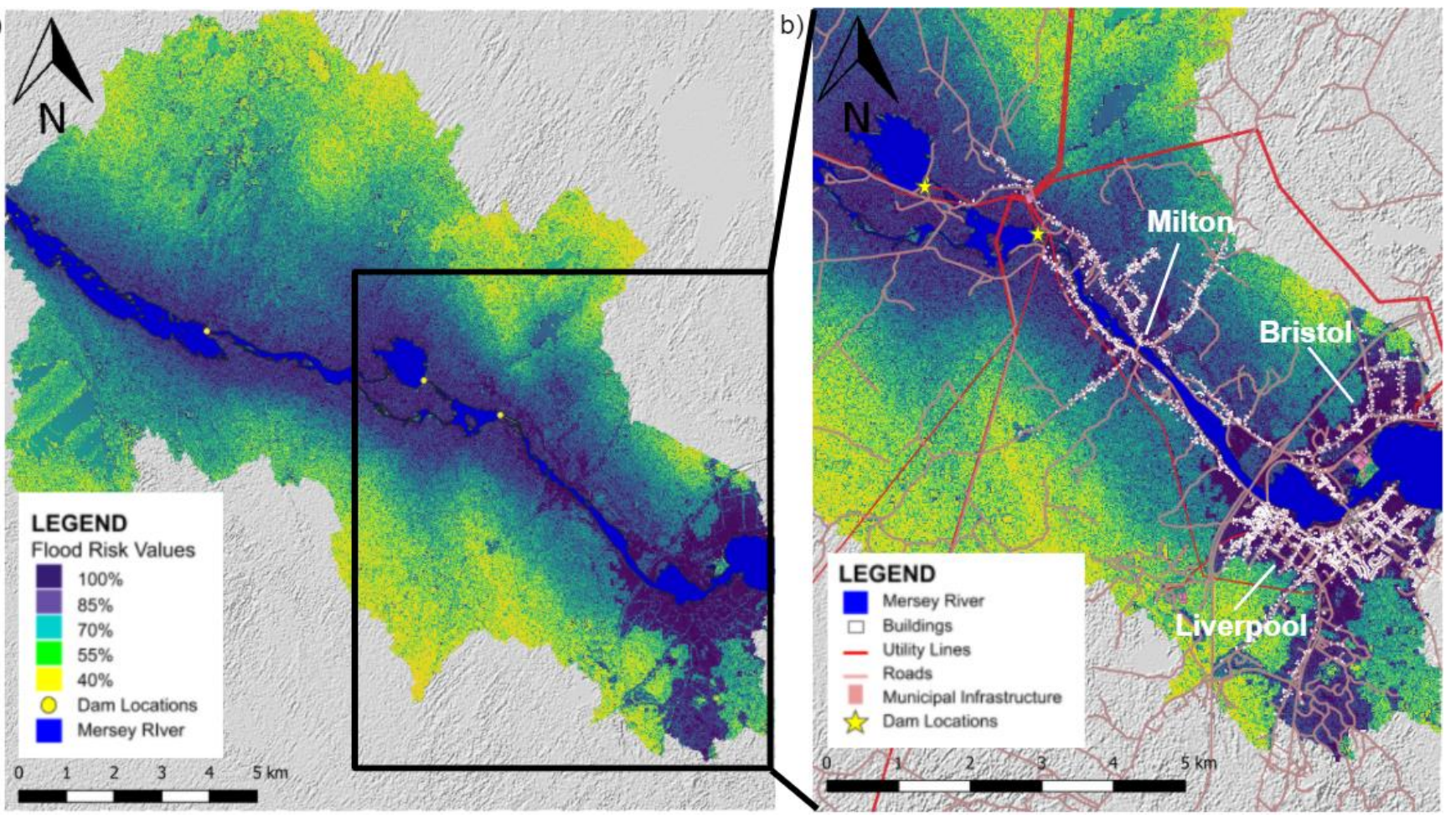

Figure 4. MCE output map showing the calculated flood risk from low to high, across the prescribed study area. Map a) displays the flood risk calculated over our floodplain extent, darker hues indicating higher risk while lighter colors indicate areas of lower to little risk. Map b) shows the flood delineation with respect to urban landmarks, roads, and cities within the county. 

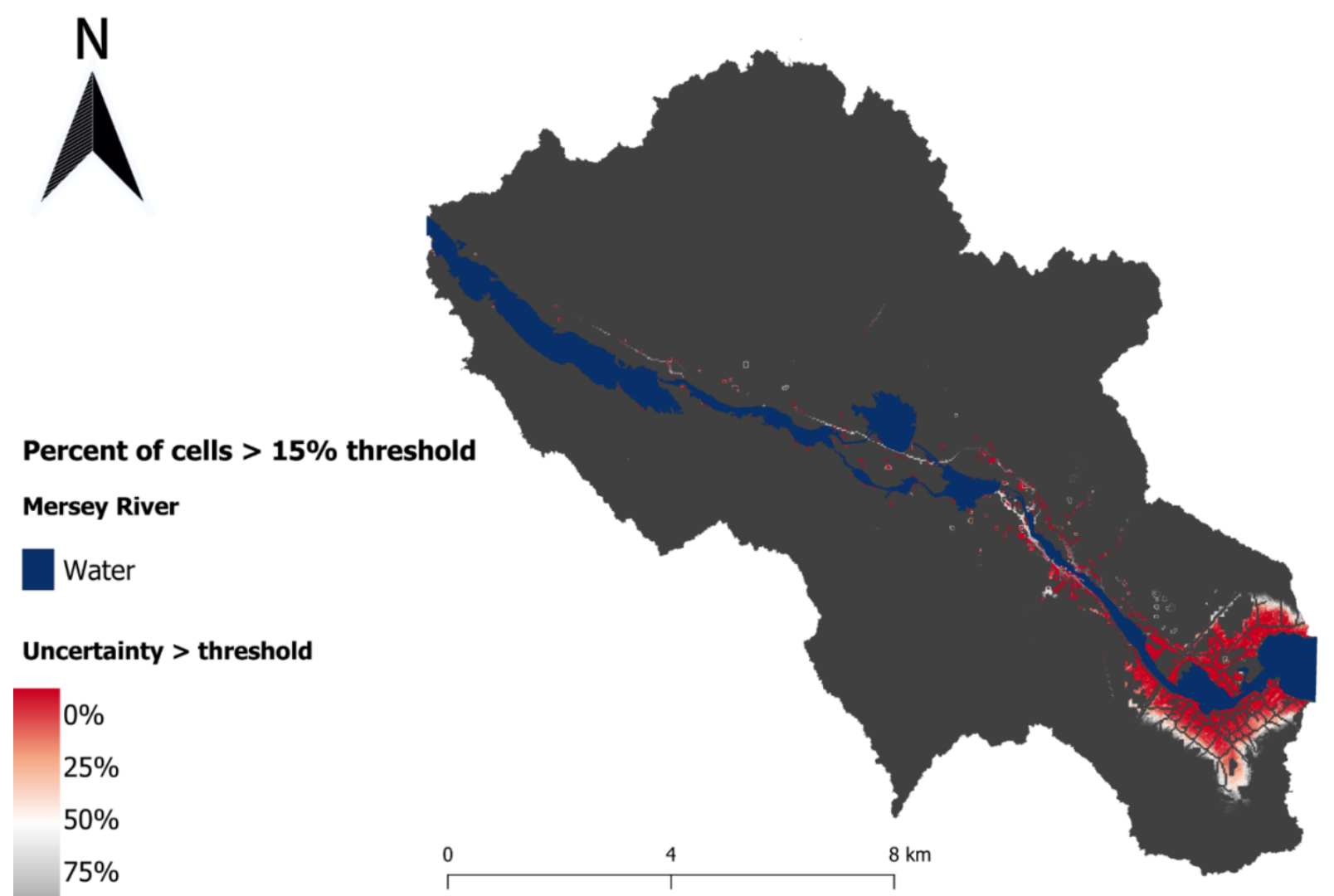

Percent of cells $>15 \%$ threshold

Mersey River

Water

Uncertainty > threshold

$0 \%$
$25 \%$
$50 \%$
$75 \%$
$100 \%$

Figure 5. a) Uncertainty map at lowest threshold limit of $15 \%$. Areas that appear in red indicate a level of low uncertainty in MCE validity, areas in grey indicate raster cells that fell below the threshold and express higher uncertainty in the MCE at these areas. 


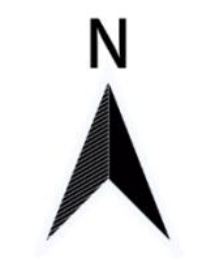

Percent of cells $>\mathbf{2 5} \%$ threshold

\section{Mersey River}

Water

Uncertainty > threshold

$0 \%$
$25 \%$
$50 \%$
$75 \%$
$100 \%$

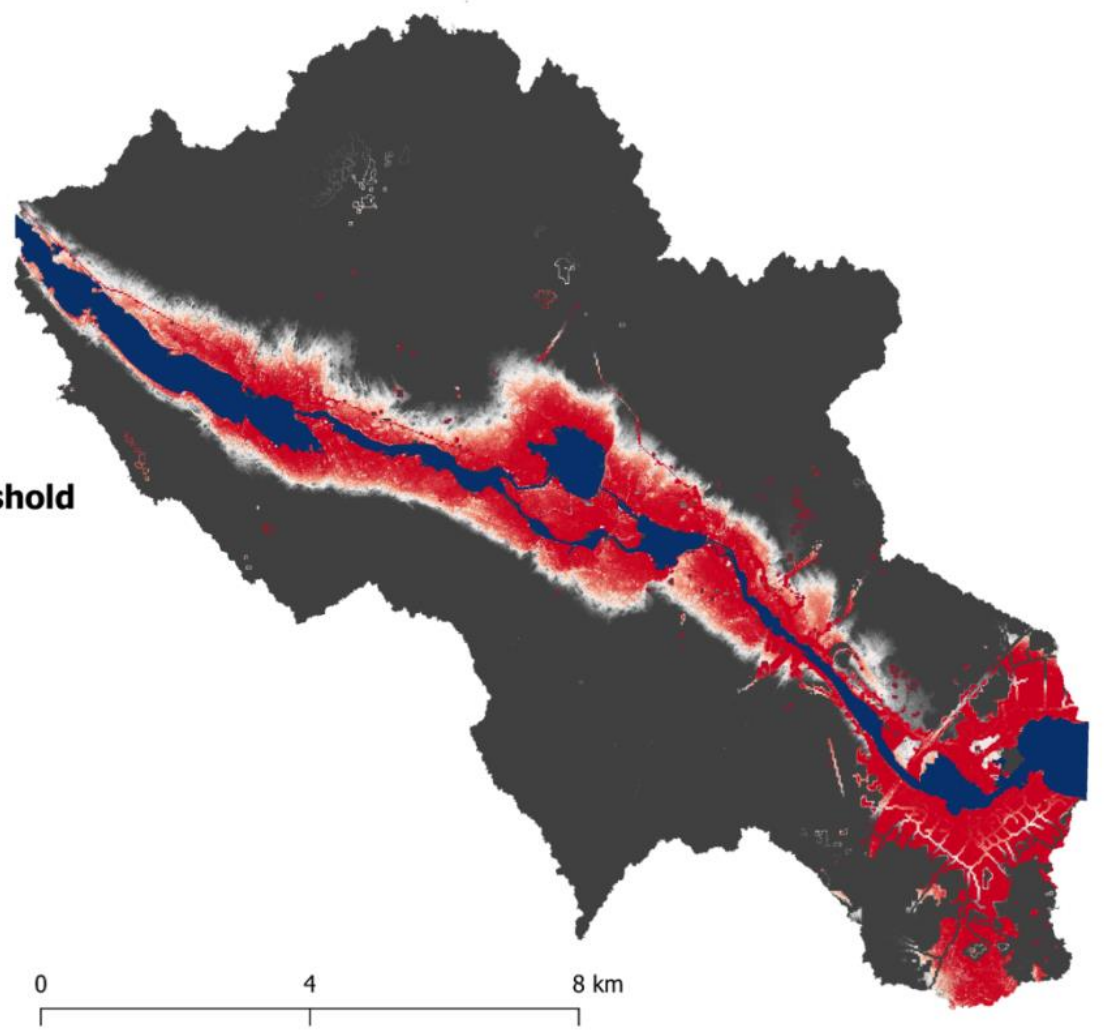

Figure 5. b) Uncertainty map at threshold limit of $25 \%$. Areas that appear in red indicate a level of low uncertainty in MCE validity, areas in grey indicate raster cells that fell below the threshold and express higher uncertainty in the MCE at these areas. 


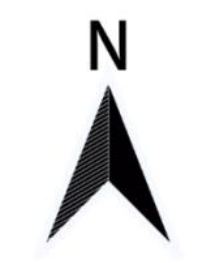

Percent of cells $>\mathbf{4 0} \%$ threshold

\section{Mersey River}

Water

Uncertainty > threshold

$0 \%$
$25 \%$
$50 \%$
$75 \%$
$100 \%$

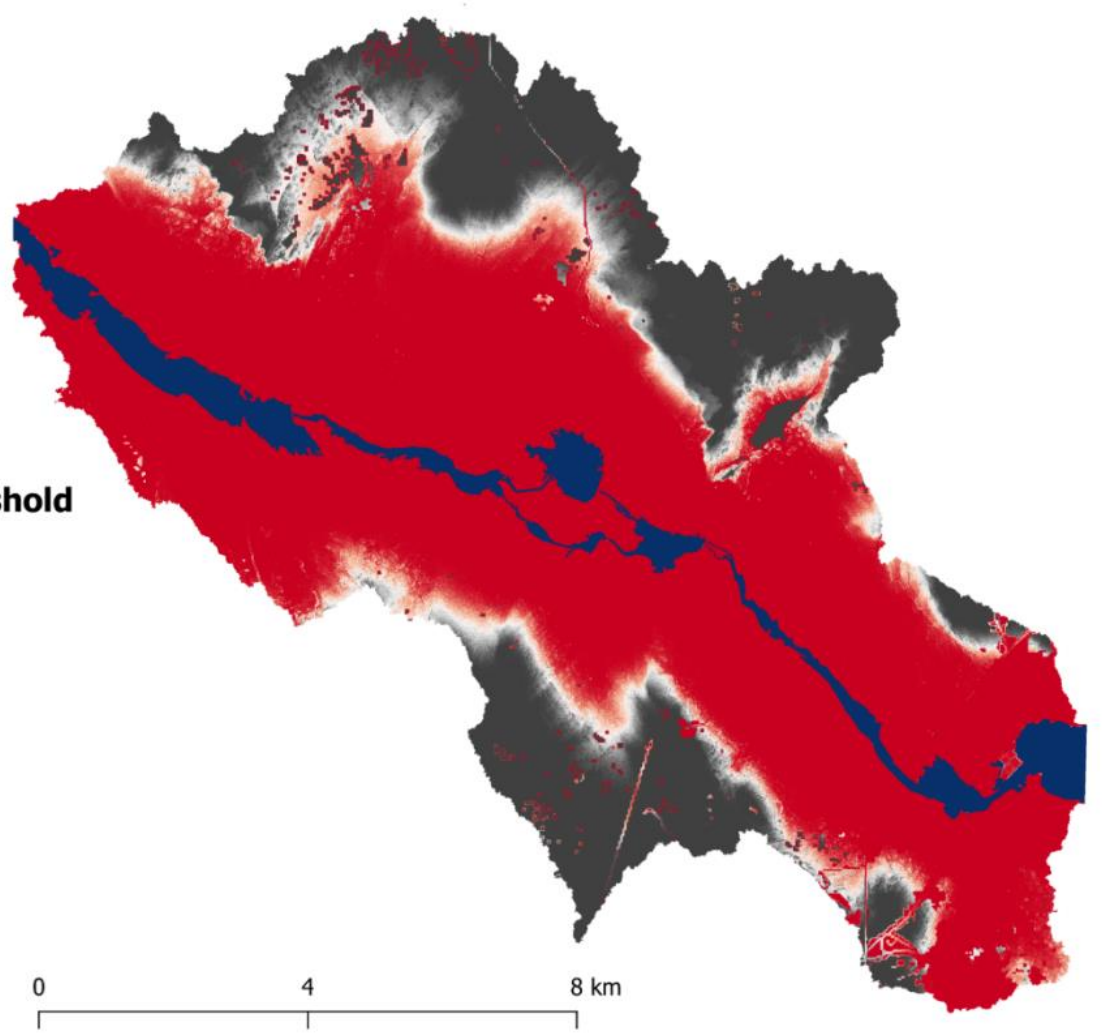

Figure 5. c) Uncertainty map at threshold limit of $40 \%$. Areas that appear in red indicate a level of low uncertainty in MCE validity, areas in grey indicate raster cells that fell below the threshold and express higher uncertainty in the MCE at these areas. 